\title{
Insertion of miniature subterminal inverted repeat-like elements in diapause-regulated genes in the Colorado potato beetle, Leptinotarsa decemlineata* (Coleoptera: Chrysomelidae)
}

\author{
George D. YOCUM, Michelle J. TOUTGES, Richard L. ROEHRDANZ and Preston J. DiHLE
}

Red River Valley Agricultural Research Center, USDA, ARS, Biosciences Research Laboratory, 1605 Albrecht Boulevard, Fargo, ND 58102-2765, USA; e-mail: george.yocum@ars.usda.gov

Key words. Chrysomelidae, Coleoptera, Leptinotarsa juncta, transposons

\begin{abstract}
Determining the genomic structure of diapause-associated transcripts (DAT) -2 and -3 led to the isolation of four novel miniature subterminal inverted repeat-like elements (MSITE): Mild-1, -2, -3 and -4. Mild-1a is inserted within the first intron of diapause protein-1. Mild-1a is $284 \mathrm{bp}$ in length, has a $14 \mathrm{bp}$ target site duplication and three sets of subterminal inverted repeats. The second element, Mild-2a, is inserted within the 3' terminus of Mild-1a. Mild-2a is $29 \mathrm{bp}$ long with a 3 bp target site duplication and one set of subterminal inverted repeats. Using primers based on Mild-1, genomic clones were developed leading to the isolation of Mild-3a. Mild-3a shares $60 \%$ identity with Mild-1a, is $253 \mathrm{bp}$ long, has a 9 bp target site duplication and has one set of subterminal inverted repeats. Mild- $4 a$ is inserted within the first intron of DAT-2 and is $227 \mathrm{bp}$ in length with a 12 bp target site duplication. Mild- $4 a$ appears to be an intermediate form between a miniature inverted repeat transposable element (MITE) and a MSITE because the $5^{\prime}$ inverted repeat is terminal (i.e., adjacent to the target site duplication) as in MITEs, but the $3^{\prime}$ inverted repeat is separated (in this case, by $33 \mathrm{bp}$ ) from the $3^{\prime}$ target site duplication as in MSITEs. The target site duplications of Mild-1, -3 and -4 families share a common conserved core of AATTT. All of the transposable elements are AT rich and are able to form hairpin structures. Within the promoter region of DAT-3 is a 163 bp sequence (Mild-1b) that shares $77 \%$ identity to the 3 ' terminus of Mild-1a. Mild-4a has identity to 25 and $53 \mathrm{bp}$ regions within the promoter of the juvenile hormone esterase $B$ gene. Southern blot analysis revealed the presence of Mild-1 and -3 elements in both Leptinotarsa decemlineata and Leptinotarsa juncta indicating that these elements are ancestral to the L. decemlineata, L. juncta separation.
\end{abstract}

\section{INTRODUCTION}

The Colorado potato beetle (CPB) Leptinotarsa decemlineata is the major pest of potato (Ferro, 1985; Hare, 1990; Cloutier et al., 1996) and also attacks tomato (Schalk \& Stoner, 1979) and eggplant (Cotty \& Lashomb, 1982; Hamilton \& Lashomb, 1996). CPB reared under short day photoperiod will feed for about 10 days after emerging as adults, and by day 20 postemergence, most of the beetles will be in diapause (de Wilde et al., 1959; Yocum et al., 2009a, b).

To further clarify the molecular basis of diapause-gene regulation in $\mathrm{CPB}$, the genomic structures of selected genes and their promoter regions are being determined. Diapause-associated transcripts (DAT) $-1,-2$ and -3 are expressed prior to day 10 postemergence in diapauseprogrammed CPB (Yocum, 2003). Sequence analysis of genomic clones of the diapause-regulated genes $D A T-2$ and -3 led to the discovery of novel miniature subterminal inverted repeat transposable-like elements (MSITEs). MSITES bear strong structural similarity to miniature inverted repeat transposable elements (MITEs) and may in some cases be an intermediate in the development of new MITEs (Tu \& Orphanidis, 2001). MITEs are small class II DNA-mediated transposable elements (TEs) that are found in organisms ranging from the nematode Cae- norhabditis elegans to human. MITEs as a class share a number of structural features such as their small size $(<1600 \mathrm{bp})$, terminal or subterminal inverted repeats, AT rich composition, lack of open reading frames, and the ability of most to form secondary structures (reviewed, Feschotte et al., 2002a). We report here the isolation of four genomic elements bearing strong similarities to MSITEs. Southern blot analyses revealed that two of these elements are present in high copy number in both $L$. decemlineata and Leptinotarsa juncta (false potato beetle).

\section{MATERIAL AND METHODS}

Insects

Leptinotarsa decemlineata is in culture at the USDA-ARS, Red River Valley Agricultural Research Center, Fargo, ND (Yocum, 2001). Leptinotarsa juncta was obtained from cultures maintained at the USDA-ARS, Insect Biocontrol Laboratory, Beltsville, MD. Leptinotarsa texana was collected by J. Patt, USDA-ARS, Weslaco, TX. Zygogramma exclamationis (sunflower beetle) was collected near Fargo, ND. Zygogramma bicolorata (Mexican beetle) was obtained from India by $\mathrm{P}$. Burange. All beetles were frozen at $-80^{\circ} \mathrm{C}$ until needed.

\section{Clone development}

The promoter region of the DAT-3 gene was isolated using gene-specific primers, the proof-reading Pfu ultra DNA

\footnotetext{
* Mention of trade names or commercial products in this article is solely for the purpose of providing specific information and does not imply recommendation or endorsement by the U.S. Department of Agriculture.
} 
polymerase (Stratagene, La Jolla, USA) and the Universal Genome Walker Kit (Clontech, Mountain View, USA). Genomic clones of transposable elements were generated using primers based on Mild-1a and Pfu ultra DNA polymerase and the Universal Genome Walker Kit. Adenine overhang was added by incubating the PCR reaction with $1.25 \mathrm{U}$ of platinum ${ }^{\circledR}$ Taq DNA polymerase for $2 \mathrm{~min}$ at $94^{\circ} \mathrm{C}$ and $10 \mathrm{~min}$ at $72^{\circ} \mathrm{C}$ (Invitrogen, Carlsbad, USA). All amplicons were cloned using the TOPO TA Cloning ${ }^{\mathrm{TM}}$ kit (Invitrogen).

\section{Southern analysis}

DNA was extracted from frozen beetles by placing them onto dry ice and removing the legs and elytrons. Ten beetles were then transferred to a prechilled mortar and pestle and ground to a fine powder in liquid nitrogen. The powder was transferred to a $50 \mathrm{ml}$ conical tube containing $20 \mathrm{ml}$ of DNA extraction buffer [10 mM Tris-HCl (pH 8.0), 0.1 M EDTA (pH 8.0), 0.5\% SDS] Twenty microliters of RNase A $(10 \mu \mathrm{g} / \mu \mathrm{l})$ were added to the extraction buffer and incubated at $37^{\circ} \mathrm{C}$ for $30 \mathrm{~min}$. Following the RNase A digestion, $100 \mu \mathrm{l}$ of Proteinase $\mathrm{K}(20 \mu \mathrm{g} / \mu \mathrm{l})$ were added to the DNA solution and incubated at $50^{\circ} \mathrm{C}$ for $3 \mathrm{~h}$. The DNA was then extracted using an equal volume of phenol : chloroform : isoamyl alcohol $(25: 24: 1)$. The DNA was spooled by adding 0.1 volume of $3 \mathrm{M}$ ammonium acetate $(\mathrm{pH}$ 5.2 ) and 1.8 volume of ice-cold $95 \% \mathrm{ETOH}$ to the aqueous phase. After drying, the DNA pellets were dissolved in 0.1 to 1 ml 1X TE [10 mM Tris-HCl (pH 8.0), 1 mM EDTA (pH 8.0)] DNA concentration and quality were determined using a NanoDrop ND-1000 spectrophotometer (NanoDrop, Wilmington, USA) and agarose gel analysis using $1 \mathrm{~Kb}+$ plus and high mass DNA ladders (Invitrogen).

Twenty micrograms of DNA were incubated for $2 \mathrm{~h}$ at $4^{\circ} \mathrm{C}$ in $140 \mu 1$ of the appropriate restriction buffer with frequent mixing.

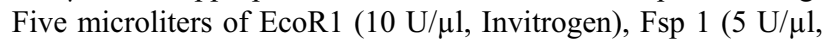
New England BioLabs, Ipswich, USA), or Xho 1 (20 U/ $\mu 1$, New England BioLabs) were then added to the appropriate reaction mixture and incubated at $37^{\circ} \mathrm{C}$ for $30 \mathrm{~min}$. After $30 \mathrm{~min}$ an additional $5 \mu \mathrm{l}$ of enzyme were added to each digestion and incubated at $37^{\circ} \mathrm{C}$ overnight. The digested DNA samples were precipitated using 0.1 volume of $3 \mathrm{M}$ sodium acetate and 2.5 volume of $95 \%$ ETOH. The DNA pellets were resuspended in $15 \mu \mathrm{l}$ of $1 \mathrm{X}$ TE and separated on a $0.7 \%$ TAE (25 mM Trisacetate, $1 \mathrm{mM}$ EDTA) agarose gel. Following separation, the gels were incubated in denaturing buffer $(0.5 \mathrm{M} \mathrm{NaOH}, 1.5 \mathrm{M}$ $\mathrm{NaCl})$ for $30 \mathrm{~min}$, neutralization buffer $[0.5 \mathrm{M}$ Tris- $\mathrm{HCl}(\mathrm{pH} 7)$, $1.5 \mathrm{M} \mathrm{NaCl}$ ] for $30 \mathrm{~min}$ then in $20 \mathrm{X} \mathrm{SSC}(3 \mathrm{M} \mathrm{NaCl}, 0.3 \mathrm{M} \mathrm{Na}$ citrate) for $30 \mathrm{~min}$. Using a TurboBlotter ${ }^{\mathrm{TM}}$ (Whatman, Clifton, USA), the DNA was transferred overnight onto positively charged nylon membrane (Roche, Indianapolis, USA) using 20X SSC as the transfer buffer. Following the transfer, the filters were UV cross-linked $\left(12,000 \mu \mathrm{J} / \mathrm{cm}^{2}\right)$ and stored at $-20^{\circ} \mathrm{C}$ until needed.

Prehybridization and hybridization were carried out at $42^{\circ} \mathrm{C}$ in Dig Easy Hyb buffer (Roche, Indianapolis, USA). Filters were screened with the following oligo probes: Mild-1a: 5'-CATGTGTCCCGAGGTGTTGAAAATGACGGT-3' or Mild-3a: 5'-CCAAACCGTTATTTCAACACCTCGACACGT-3'. Probes were labeled using Dig oligonucleotide $3^{\prime}$-end labeling kit and were detected using the Dig High Prime DNA labeling and Detection Start Kit II as described in the manufacturers protocols (Roche).

\section{Bioinformatics}

The Blastn and Blastx programs (Altschul et al., 1997) were used to search the GenBank sequence repository for sequence identity. Sequence alignments and percent identity calculations

\section{A}

DAT-3 GAATCATAACTGTTCATAACCCTGAATACCTTCAACAACTATAAATTACT

Mild-1a $* * * * * * \mathrm{~A} * * * * * * * * * \mathrm{G} * * * * * * \mathrm{CA} * * * * * * * * * * \mathrm{GA} * * * * * \mathrm{G} * * * * * \mathrm{~A} *$ DAT-3 TGTGATGCACTGTTTGAAACCTTTGGTGTAGTAATTGATATT-ACTGGGG

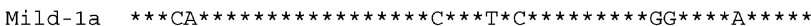
DAT-3 TTTTCTCCCAACACCAAACCGTTATTCT-AACACCTCG--ACACGTGTTT

Mild-1a $* * \mathrm{G} * * * * * * * \mathrm{C} * * * * * * * * * *{ }_{\mathrm{A}} * * * * \mathrm{G} * * * * \mathrm{TTT} *{ }^{\mathrm{T}}{ }^{*} \mathrm{~T} * \mathrm{C}{ }^{*} \mathrm{CC}-* *$ DAT-3 CGATCACCAAGTGATCATCTTCGAGAGAAAGACGAAACTGTTTGATGAAA

\section{B}

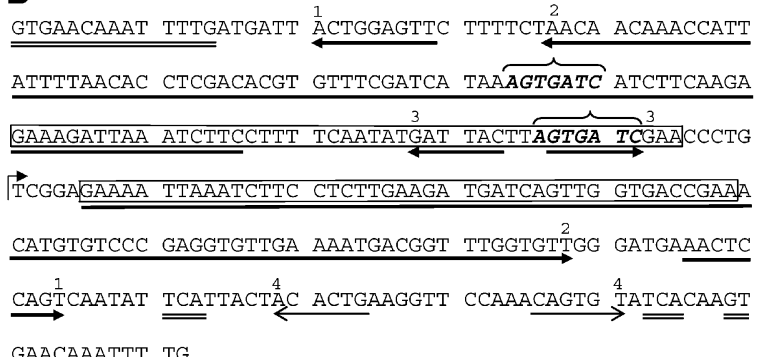

GAACAAATTT TG

Fig. 1. Sequence alignment of Mild- $1 a$ (with embedded Mild-2a) with the promoter region of DAT-3 and the genomic structure of Mild-1a with embedded Mild-2a. (A) Alignment of Mild-1 $a$ and Mild-2a with DAT-3 promoter region; underline highlights Mild-2a; (*) identical nucleotide; (-) insertion or deletion. (B) Genomic structure of Mild-1 $a$ and $-2 a$; the target site duplications are indicated by double underlines; Mild-1 $a$ is longer than Mild-2a. The subterminal inverted repeats are indicated by arrows, corresponding inverted repeats are labeled with the same number: heavy arrows for Mild-1a, and thin arrows for Mild-2a. A seven bp internal direct repeat is in bold italic under brackets and the 45 bp internal direct repeat is boxed. The bent arrow indicates the region of similarity between Mild-1 $a$ and the promoter region of $D A T-3$.

were carried out using ContigExpress and AlignX (Invitrogen). MSITE secondary structure analysis was performed using Mfold (Zuker et al., 1999; Zuker, 2003).

\section{Phylogenetic analysis}

DNA from individual insects was amplified using standard PCR conditions described previously (Roehrdanz et al., 2010). Primers were LCO-1490: 5'-TTTCTACAAATCATAAAGATA TTGG-3' and HCO-2198: 5'-TGATTTTTTGGTCACCCTGA AGTTTA-3' which flank the mitochondrial cox 1 barcode region. PCR products were sequenced by the Iowa State University DNA sequencing facility in Ames, IA. GenBank accession numbers for the sequences are: Leptinotarsa decemlineata, HQ605768 (CPB3704), HQ605769 (CPB3948); Leptinotarsa juncta, HQ605770 (FPB-A), HQ605771 (FPB4053); Leptinotarsa texana, $\underline{\mathrm{HQ} 605774}$ (LTX3854), $\underline{\mathrm{HQ} 605775}$ (LTX3855); Zygogramma exclamationis, HQ605776 (SFB3809), $\underline{\mathrm{HQ605777}}$ (SFB3852), HQ605778 (SFB3853); Zygogramma bicolorata, HQ605772 (ZBC3846), HQ605773 (ZBC3847). Additional GenBank sequences used in analysis were EU498301 (Diabrotica virgifera) and AJ312413 (Tribolium castaneum).

The evolutionary history of the chrysomelids and Tribolium was inferred using the Minimum Evolution method (Rzhetsky \& Nei, 1992). The bootstrap consensus tree inferred from 1000 replicates is taken to represent the evolutionary history of the taxa analyzed (Felsenstein, 1985). Branches corresponding to partitions reproduced in less than $50 \%$ bootstrap replicates are collapsed. The percentage of replicate trees in which the associated taxa clustered together in the bootstrap test are shown next 
A

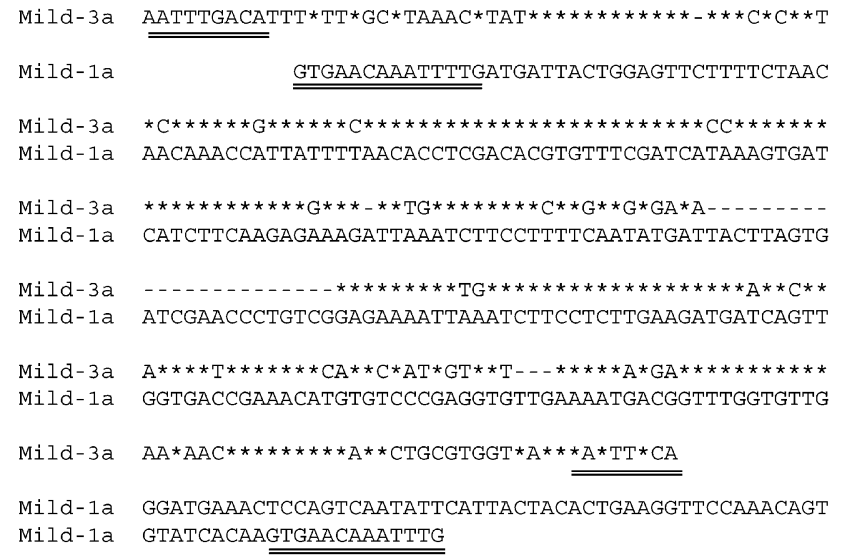

B

AATTTGACAT TTTTTAGCAT AAACGTATAT TACTGGAGTT TTTCCCAATA CCAAACCGTT ATTTCAACAC CTCGACACGT GTTTCGATCA CCAAGTGATC ATCTTdAAGA GGAAGTTTGA TCTTCCTCTT GAAGA GA AAG AGGAAATTTG $\overline{\text { ATCTTCCTCT TGAAGATGAA CACTTAGTGA TCGAAACACA TGCCATGGTG }}$ TTAAAATAAG AGTTTGGTGT TGAAAAACAA CTCCAGTAAA CTGCGTGGTC AACAATTTACA

Fig. 2. Sequence alignment of Mild-1a (Mild-2a removed) with Mild-3a and the genomic structure of Mild-3a. (A) Alignment of Mild-1a and Mild-3a; $\left(^{*}\right)$ identical nucleotide; (-) insertion or deletion. (B) Genomic structure of Mild-3a; the target site duplications are indicated by double underlines. The subterminal inverted repeats are indicated by arrows. The boxed sequences are the internal direct repeats.

to the branches. The evolutionary distances were computed using the Maximum Composite Likelihood method (Tamura et al., 2004) and are in the units of the number of base substitutions per site. There were a total of 658 positions in the final dataset. Phylogenetic analyses were conducted in MEGA4 (Tamura et al., 2007).

\section{RESULTS}

\section{Miniature inverted repeat transposable element}

BlastN analysis of the DAT-3 promoter region (GenBank accession no. DQ011146) revealed a 163 bp region 1411 bp upstream of the DAT-3 deduced TATA box with $77 \%$ identity to the intron of diapause protein-1 (DP-1) from L. decemlineata (Koopmanschap et al., 1995, GenBank accession no. X86074) (Fig. 1A). Inspection of the region of the $D P-1$ gene with identity to the $D A T-3$ promoter region revealed the presence of a transposable element (TEL)-like sequence embedded in the first intron of DP-1 at nucleotides 1204 to 1487 (Fig. 1B). The 284 bp TEL-like sequence has three sets of imperfect subterminal inverted repeats (SIRs) 9, 83 and 6 bp in length with 89 , 83 and $83 \%$ identity respectively between the $5^{\prime}$ and $3^{\prime}$ counterparts (Fig. 1B). The TEL is AT rich (63\%) and is flanked by perfect $14 \mathrm{bp}$ (GTGAACAAATTTTG) target site duplications (TSD). Mfold analysis of this sequence revealed that it would form a hairpin structure with a $\Delta \mathrm{G}$ of $-69.5 \mathrm{kcal} / \mathrm{mol}$ (Zuker et al., 1999). This $284 \mathrm{bp}$ TELlike sequence bears strong similarities to MSITEs. Because of its size, its ability to form a secondary struc-
A

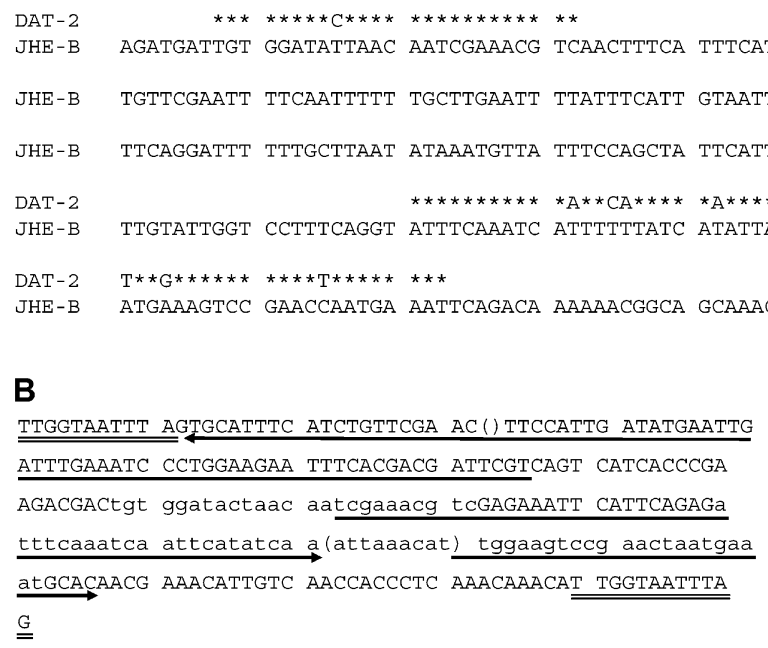

Fig. 3. Regions of sequence identity between $D A T-2$ intron, the promoter region of $J H E B$ and the genomic structure of Mild-4a. (A) Identity between Mild-4a and JHEB promoter region; (*) identical nucleotide. (B) Genomic structure of Mild- $4 a$; the target site duplications are indicated by double underlines. The inverted repeats are indicated by arrows. Lower case letters indicates sequences in common between Mild- $4 a$ and the $J H E B$ promoter region. Brackets indicate position of the indel.

ture, and its structural similarity to MSITEs, we are designating this element Mild-1a (miniature subterminal inverted repeat transposable-like element Leptinotarsa decemlineata). Mild-1a also has two internal direct repeats: a perfect 7 bp repeat and an imperfect 45 bp repeat ( $82 \%$ identity) (Fig. 1B). Mild-1a is not structurally symmetrical in that the distance between the 5' TSD and SIR is only $6 \mathrm{bp}$ whereas there are $44 \mathrm{bp}$ between the 3' SIR and TSD. Upon close inspection it appears that a 29 bp MSITE-like sequence is inserted in the $3^{\prime}$ region of Mild-1a. The inserted MSITE (Mild-2a) has a 3 bp TSD (TCA) and a 6 bp SIR and is AT rich (62\%) (Fig. 1B) and can form a hairpin with a $\Delta \mathrm{G}$ of $-4.6 \mathrm{kcal} / \mathrm{mol}$. Alignment of the $163 \mathrm{bp}$ promoter region of DAT-3 with Mild-1a reveals that this region has high similarity to Mild-1a, containing all of Mild-2a and the 3' half of Mild-1a. The $3^{\prime}$ TSD is degraded but still discernable (Fig. 1A). This element inserted within the promoter region of $D A T-3$ is being designated as Mild-1b.

Other genomic clones developed as a part this project led to the isolation of a $708 \mathrm{bp}$ clone with $67 \%$ identity to Mild-1a without the Mild-2a insertion (TEL sequence shown, Fig. 2A). The clone contains a copy of another complete MSITE-like sequence (Fig 2B). This element is $253 \mathrm{bp}$ in length, 60\% AT, and has an imperfect $9 \mathrm{bp}$ TSD (AATTTG/-ACA), a 29 bp imperfect internal direct repeat (97\% identity) and one set of SIRs $109 \mathrm{bp}$ in length $(81 \%$ identity) that can form a hairpin structure with a $\Delta \mathrm{G}$ of $-72.9 \mathrm{kcal} / \mathrm{mol}$ (Fig. 2B). This element was designated Mild-3a (GenBank accession no. DQ011149).

Blastn analysis of a genomic clone of the first intron of the L. decemlineata DAT-2 gene (Yocum, 2003) revealed two regions, a 25 and a 53 bp stretch with 96 and $85 \%$ 


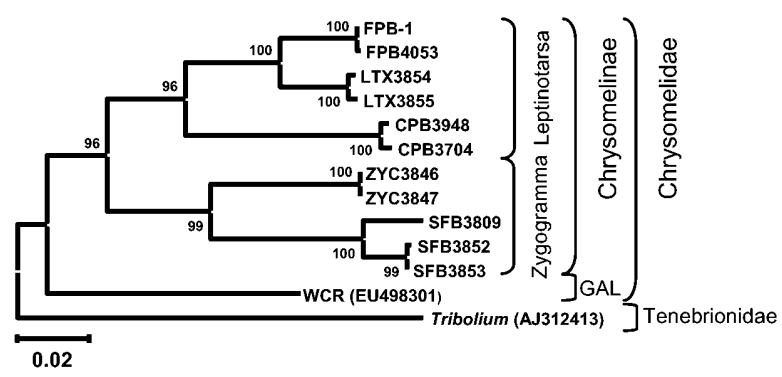

Fig. 4. Minimum evolution tree using mitochondrial coxl sequences of Chrysomelids (Leptinotarsa, Zygogramma, Diabrotica) and a Tenebrionid (Tribolium). GAL, Galerucinae. Scale is the number of nucleotide substitutions per site.

identity within the promoter of $L$. decemlineata juvenile hormone esterase B gene (JHEB) (Vermunt et al., 1998, GenBank accession no. AF39135) (Fig. 3A). Examining these regions led to identification of another complete MSITE-like TEL in the first intron of $D A T-2$. The TEL is 227 bp in length with perfect 12 bp TSD (TTGGTAATTTAG) and is AT rich (64\%). This TEL has an odd arrangement of inverted repeats. The 5 ' inverted repeat is terminal, being adjacent to the TSD, while the 3 ' inverted repeat is separated by $33 \mathrm{bp}$ from the $3^{\prime}$ TSD (Fig. 3B). Aligning the $5^{\prime}$ inverted repeat with the two $3^{\prime}$ inverted repeats including the $9 \mathrm{bp}$ indel yielded identity of $88 \%$ (Fig. 3B). Mfold analysis of this sequence revealed that it would form a hairpin structure with a $\Delta G$ of -58.4 $\mathrm{kcal} / \mathrm{mol}$. This new MSITE-like sequence is being designated as Mild-4a (GenBank accession no. EF121856). The TSDs of Mild-1a, Mild-3a and Mild-4a have a common conserved core of AATTT. A Blastn search restricted to Tribolium castaneum genome using Mild-1, $-2,-3$ and -4 yielded no significant results. Comparison of mitochondrial coxl sequences indicates a genetic distance between $L$. decemlineata and T. Castaneum of 0.214 while the distance between $L$. decemlineata and L. juncta is 0.102 .

\section{Southern analysis}

Probes designed against Mild-1 $a$ and Mild-3 revealed that these two elements are throughout the genome of both L. decemlineata and L. juncta (Fig. 5, Only Mild-3 results are shown, Mild-1 $a$ gave similar results to Mild-3). The heavy smearing on the southern blots indicates that Mild-1 $a$ and Mild-3 elements are common throughout the genomes in these two beetle species. The lesser genetic distance between L. juncta and L. texana (0.040) suggests that the latter species could also have these elements.

\section{CONCLUSIONS AND DISCUSSION}

Transposable elements are major component of eukaryotic genomes examined to date. Transposons are grouped into broad classes based on the means in which they move within the genome. Class 1 transposons move through a RNA intermediate involving several different enzymes. Class 2 transposons' means of transposition is by a "cut and paste" reaction facilitated by a transposase. Transposons can be further subdivided above the family

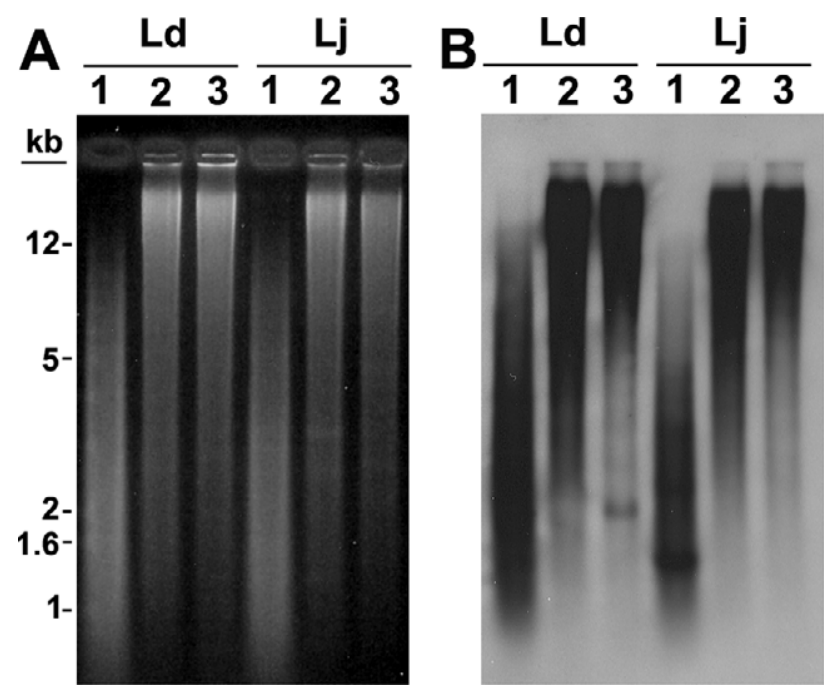

Fig. 5. Southern blot analysis of the putative transposable element Mild-3a in Leptinotarsa decemlineata (Ld) and Leptinotarsa juncta $(\mathrm{Lj})$. Twenty micrograms of genomic DNA were digested with EcoR 1 (1), Fsp 1 (2), or Xho 1 (3) and separated on a $0.7 \%$ agarose gel. Ethidium bromide stained agarose gel (A), southern filter probe with a digoxigenin-labeled probe (B). Probe against Mild-1a gave results similar to Mild-3a but at a somewhat lower level of hybridization (data not shown).

level by if they are autonomous or nonautonomous elements. Nonautonomous elements lack the open reading frames needed to encode the enzymes necessary for transposition (Feschotte et al., 2002b). Nonautonomous elements are formed from internal deletions of autonomous transposons. Individual MITE families have evolved from either the IS630-Tc1-mariner or PIF-Harbinger of autonomous transposons (Feschotte et al., 2002b; Turcotte \& Bureau, 2002; Feschotte et al., 2005; Menzel et al., 2006). Both of these superfamilies of transposons are found in insects (Tu, 2005).

MITEs were first isolated from maize, Zea mays (Bureau \& Wessler, 1992). Though most extensively investigated in plants and insects, MITEs have also been isolated from the fungus Neurospora crassa (Yeadon \& Catcheside, 1995), the frogs Xenopus borealis and Xenopus leavis (Unsal \& Morgan, 1995), the nematode Caenorhabditis elegans (Oosumi et al., 1996), the fish Ctenopharyngodon idellus, Cyprinus carpio, Danio aequipinnatus, Danio albolineatus, Danio latipes, Danio rerio and Hypophthalmichthys molitrix (Izsvak et al., 1999) and humans, Homo sapiens (Morgan, 1995; Smit \& Riggs, 1996). The copy number of an individual MITE can vary greatly from a few ( 8 copies of $m P I N G$ in the Indica cultivar 93-1 of rice, Oryza sativa) (Jiang et al., 2003; Yu et al., 2002) to over 6,000 copies of $m P I F$ in maize (Zhang et al., 2001). In plants screened to date, MITEs as a class are a major component of the total TEL population within their genome. In Arabidopsis the MITE composition is $25 \%$ of total TELs, and MITEs make up approximately $75 \%$ of all TELs in the rice genome, with over 90,000 copies of individual MITEs (see Fig. 1 in Jiang et al., 2004). The species distribution of individual MITE families can vary greatly: Ditto, Wanderer, 
Explorer, Snap, Crackle and Pop are restricted to rice (Bureau et al., 1996; Song et al., 1998; Yang et al., 2001), and Stowaway is found in both monocots and dicots (Bureau \& Wessler, 1994b). Tourist-like MITEs are found in grasses, Arabidopsis, C. elegans and insects (Bureau \& Wessler, 1992, 1994a; Le et al., 2000, 2001; $\mathrm{Tu}, 2005)$. A transposable element is classified as a MITE based on seven normally seen structural characteristics and not on its sequence identity (reviewed, Feschotte et al., 2002a). (1) MITEs are characterized by their small size varying from 70 to $1,600 \mathrm{bp}$. The putative MSITEs described here are 29 to 284 bp. At 29 bp, Mild-2a would be the smallest MSITE reported in the literature. (2) Most MITEs have TIRs, although a few families such as Mint1 (Feschotte \& Mouches, 2000), Pop and Crackle (Song et al., 1998) and Microuli (Tu \& Orphanidis, 2001) lack TIRs and have SIRs instead. Mild-1, -2, -3 and -4 clearly fall in the small group of MITEs lacking TIRs and having SIRs instead. Mild- $4 a$ appears to be an intermediate between a true MITE and a MSITE, in that its inverted repeat is terminal only on one side and it has a $33 \mathrm{bp}$ insert between the inverted repeat and the TSD on the other side. Tu \& Orphanidis (2001) proposed that MSITEs may serve as an intermediate for development of some novel MITEs either through mutation or recombination events: Mild-4a's structure gives credence to this theory. (3) Many MITEs have the ability to form a hairpin-like secondary structure, a characteristic shared by Mild-1a, $-2 a,-3 a$ and -4a. (4) MITEs are nonautonomous elements lacking an open reading frame. A Blastx search (March 25, 2010) failed to find identity to any known entries in GenBank for Mild-1a, $-2 a,-3 a$ or $-4 a$. (5) MITEs have preferred target sites from 2 to $9 \mathrm{bp}$ in length that are duplicated upon insertion so that the MITE is flanked by direct repeats (TSD). The direct repeats flanking the $L$. decemlineata Mild-elements vary between 3 and 14 bp in length with Mild-1, -3 and -4 sharing the common core sequence of AATTT. (6) The AT composition of the Mild elements varies between 60 and $64 \%$, a range commonly seen in other MITEs. (7) Individual members of a MITE family can vary in size.

A distinguishing characteristic of Mild-1a and $-3 a$ is their internal direct repeats. Some of these internal direct repeats are relatively large in relationship to the overall size of the MSITE in which they are found, 45 and $29 \mathrm{bp}$ for Mild-1 $a$ and - $3 a$ respectively. The large internal direct repeats are located just on either side of the hairpin loop. These repeats are substantially longer than the pentameric internal direct repeats found in Tourist (Bureau \& Wessler, 1992).

Besides these structural similarities, certain propensities of MITEs have emerged in the literature. MITEs target low copy sequences and therefore are commonly inserted near or within the noncoding regions of genes (Jiang et al., 2003, 2004). This propensity of MITEs to insert within the noncoding regions of genes led to the initial identification of Mild-1 and -2 within the first intron of $D P-1$, and Mild-4 within the first intron of DAT-2. Besides their preference for noncoding regions around genes, MITEs commonly insert within other MITEs. The insertion of one MITE into another is a common enough occurrence that it has led to the identification of new MITE families (Bureau \& Wessler, 1994b; Feshotte \& Mouches, 2000; Petersen \& Seberg, 2000; Tu, 1997). This nesting behavior led Feshotte \& Mouches (2000) to suggest that MITES may be preferred targets for insertion by other MITEs. The presence of Mild-2a within the 3' end of Mild-1a is an example of this nesting of MITEs. The heavy smearing observered in the Southern blots would indicate that the elements Mild-1 and Mild-3 are present in high copy numbers in these two congeneric species. Southern results of MITEs in other species varies from distinct bands to smears as seen in L. decemlineata and L. juncta (Bureau \& Wessler, 1992; Braquart et al., 1999; Yang et al., 2001; Menzel et al., 2006; Remigereau et al., 2006).

TEs are a major component of most eukaryotic genomes varying from approximately $2 \%$ for C. elegans (Waterston \& Sulston, 1995) to approximately 58\% in maize (SanMiguel et al., 1996; Messing et al., 2004). By their sheer number, TEs have a major influence on genome size and architecture, thereby affecting an organism's phenotypic traits by mutagenesis, genomic rearrangement (review: Kidwell \& Lisch, 2001, 2002) and nucleotypic effects (review: Gregory \& Hebert, 1999). The insertions of MITE-like elements in the promoter regions of $D A T-3$ and $J H E B$ and in introns of $D A T-2$ and $D P-1$ would suggest that TEs may have played a role in the evolutionary development and phenotypic expression of diapause in the Colorado potato beetle. This possible role for TEs in L. decemlineata diapause is emphasized by the fact that the JHEB gene regulates the expression of diapause by controlling juvenile hormone titers (Denlinger et al., 2005). Determining what the exact role, if any, TEs play in the $L$. decemlineata diapause awaits the sequencing of its genome and extensive field studies.

In conclusion: (1) Even with our current limited information about $L$. decemlineata and L. juncta genomes, MITE-like elements appear to be common in both. (2) The presence of Mild-1 and -3 elements in both L. decemlineata and L. juncta indicate that these elements occurred in their common ancestor. (3) The presence of these elements with the promoter regions and introns of diapauseregulated genes would indicate a possible role of TEs in the evolution and regulation of diapause

ACKNOWLEDGEMENTS. We thank L.B. Yocum for her editing of the various drafts of this manuscript. We thank D. Weber for supplying the Leptinotarsa juncta used in the project, J. Patt for the L. texana, and P. Burange for obtaining the Zygogramma bicolorata. We also wish to acknowledge the outstanding technical assistance of M.L. Larson, T.M. Becker, and S.G. Sears, USDA-ARS Fargo, ND.

\section{REFERENCES}

Altschul S.F., Madden T.L., SchäFfer A.A., Zhang J., Zhang Z., Miller W. \& Lipman D.J. 1997: Gapped Blast and PSIBlast: a new generation of protein database search programs. Nucl. Acids Res. 25: 3389-3402. 
Braquart C., Royer V. \& Bouhin H. 1999: DEC: a new miniature inverted-repeat transposable element from the genome of the beetle Tenebrio molitor. Insect Mol. Biol. 8: 571-574.

BuREAU T.E. \& WessLer S.R. 1992: Tourist: a large family of small inverted repeat elements frequently associated with maize genes. Plant Cell 4: 1283-1294.

Bureau T.E. \& Wessler S.R. 1994a: Mobile inverted-repeat elements of the Tourist family are associated with genes of many cereal grasses. Proc. Natl. Acad. Sci. USA 91: 1411-1415.

Bureau T.E. \& Wessler S.R. 1994b: Stowaway: A new family of inverted repeat elements associated with the genes of both monocotyledonous and dicotyledonous plants. Plant Cell 6: 907-916.

Bureau T.E., Ronald P.C. \& Wessler S.R. 1996: A computerbased systematic survey reveals the predominance of small inverted-repeat elements in wild-type rice genes. Proc. Natl. Acad. Sci. USA 93: 8524-8529.

Cloutier C., Jean C. \& Bauduin F. 1996: More biological control for a sustainable potato pest management. In Duchesne R.-M. \& Boiteau G. (eds): Proceedings of the Symposium 1995 Potato Pest Control. Agri-Food Canada, Canada Agriculture, Quebec, pp. 15-52.

CotTy S. \& Lashomb J. 1982: Vegetative growth and yield response of eggplant to varying first generation Colorado potato beetle densities. J. N.Y. Entomol. Soc. 90: 220-228.

Denlinger D.L., Yocum G.D. \& Rinehart J.P. 2005: Hormonal control of diapause. In Gilbert L.I., Iatrou K. \& Gill S.S. (eds): Molecular Insect Sciences. Vol. 3. Endocrinology. Elsevier, Amsterdam, pp. 615-650.

Felsenstein J. 1985: Confidence limits on phylogenies: An approach using the bootstrap. Evolution 39: 783-791.

Ferro D.N. 1985: Pest status and control strategies of the Colorado potato beetle. In Ferro D.N. \& Voss R.N. (eds): Proceedings of the Symposium on the Colorado Potato Beetle, $17^{\text {th }}$ International Congress of Entomology. Massachusetts Agricultural Experimental Station Research Bulletin 704, pp. $1-8$.

Feschotte C. \& Mouches C. 2000: Recent amplification of miniature inverted-repeat transposable elements in the vector mosquito Culex pipiens: characterization of the Mimo family. Gene 250: 109-116.

Feschotte C., Zhang X. \& Wessler S.R. 2002a: Miniature inverted-repeat transposable elements and their relationship to established DNA transposons. In Craig N.L., Craigie R., Gellert M. \& Lambowitz A.M. (eds): Mobile DNA II. ASM Press, Washington, D.C., pp. 1147-1158.

Feschotte C., Jiang N. \& Wessler S.R. 2002b: Plant transposable elements: where genetics meets genomics. Nature Rev. Genet. 3: 329-341.

Feschotte C., Osterlund M.T., Peeler R. \& Wessler S.R. 2005: DNA-binding specificity of rice mariner-like transposases and interactions with Stowaway MITES. Nucl. Acids Res. 33: 2153-2165.

Gregory T.R. \& Hebert P.D.N. 1999: The modulation of DNA context: proximate causes and ultimate consequences. Genome Res. 9: 317-324.

Hamilton G.C. \& Lashomb J. 1996: Comparison of conventional and biological control intensive pest management programs on eggplant in New Jersey. Fla. Entomol. 79: 488-496.

HARE J.D. 1990: Ecology and management of the Colorado potato beetle. Annu. Rev. Entomol. 35: 81-100.

Izsvak Z., Ivics Z., Shimoda N., Mohn D., Окамоto H. \& HACKETT P.B. 1999: Short inverted-repeat transposable elements in teleost fish and implications for a mechanism of their amplification. J. Mol. Evol. 48: 13-21.
Jiang N., Bao Z., Zhang X., Hirochika H., Eddy S.R., McCouch S.R. \& Wessler S.R. 2003: An active DNA transposon family in rice. Nature 241: 163-167.

Jiang N., Feschott C., Zhang X. \& Wessler S.R. 2004: Using rice to understand the origin and amplification of miniature inverted repeated transposable elements (MITEs). Curr. Opion. Plant Biol. 7: 115-119.

Kidwell M.G. \& Lisch D.R. 2001: Perspective: transposable elements, parasitic DNA, and genome evolution. Evolution 55: $1-24$.

Kidwell M.G. \& Lisch D.R. 2002: Transposable elements as sources of genomic variation. In Craig N.L., Craigie R., Gellert M. \& Lambowitz A.M. (eds): Mobile DNA II. ASM Press, Washington, D.C., pp. 59-90.

Koopmanschap A.B., Lammers J.H.M. \& De Kort C.A.D. 1995: The structure of the gene encoding diapause protein 1 of the Colorado potato beetle (Leptinotarsa decemlineata). J. Insect Physiol. 41: 509-518.

Le Q.H., Wright S., Yu Z. \& Bureau T. 2000: Transposon diversity in Arabidopsis thaliana. Proc. Natl. Acad. Sci. USA 97: 7376-7381.

Le Q.H., Turcotte K. \& Bureau T. 2001: Tc8, a Tourist-like transposon in Caenorhabditis elegans. Genetics 158: $1081-1088$

Menzel G., Dechyeva D., Keller H., Lange C. \& Himmelbauer H. 2006: Mobilization and evolutionary history of miniature inverted-repeat transposable elements (MITEs) in Beta vulgaris L. Chromosome Res. 14: 831-844.

Messing J., Bharti A.K., Karlowski W.M., Gundlach H., Kim H.R., Yu Y., Wei F., FuKs G., Soderlund C.A., MaYer K.F.X. \& Wing R.A. 2004: Sequence composition and genome organization of maize. Proc. Natl. Acad. Sci. USA 101: 14349-14354.

Morgan G.T. 1995: Identification in the human genome of mobile elements spread by DNA mediated transposition. $J$. Mol. Biol. 254: 1-5.

Oosumi T., Garlick B. \& BelKnaP W.R. 1996: Identification of putative nonautonomous transposable elements associated with several transposon families in Caenorhabditis elegans. $J$. Mol. Evol. 43: 11-18.

Petersen G. \& Seberg O. 2000: Phylogenetics evidence for excision of stowaway miniature inverted-repeat transposable elements in Triticeae (Poaceae). Mol. Biol. Evol. 17: $1589-1596$

Remigereau M.-S., Robin O., Siljak-Yakovlev S., Sarr A., ROBERT T. \& LANGIN T. 2006: Tuareg, a novel miniatureinverted repeated family of pearl millet (Pennisetum glaucum) related to the PIF superfamily of maize. Genetica 128: $205-216$.

Roehrdanz R., Heilmann L., Senechal P., Sears S. \& Evenson P. 2010: Histone and ribosomal RNA repetitive gene clusters of the boll weevil are linked in a tandem array. Insect Mol. Biol. 19: 463-471.

RzHETSKy A. \& Nei M. 1992: A simple method for estimating and testing minimum evolution trees. Mol. Biol. Evol. 9: 945-967.

SanMiguel P., Tkhonov A., JiN Y.-K., Motchoulskaia N., Zakharov D., Melake-Berhan A., Springer P.S., Edwards K.J., Lee M., Avramova Y. \& Bemmeten J.L. 1996: Nested retrotransposons in the intergenic region of the maize genome. Science 274: 765-768.

Schalk J.M. \& STONER A.K. 1979: Tomato production in Maryland: Effects of different densities of larvae and adults of the Colorado potato beetle. J. Economic Entomol. 72: 826-829. 
Smit A.F.A. \& Riggs A.D. 1996: Tiggers and DNA transposon fossils in the human genome. Proc. Natl. Acad. Sci. USA 93 1443-1448

Song W.-Y., Pi L.-Y., BuREau T.E. \& Ronald P.C. 1998: Identification and characterization of 14 transposon-like elements in the noncoding region of members of the Xa21 family of disease resistance genes in rice. Mol. Gen. Genet. 258: 449-456.

Tamura K., Nei M. \& Kumar S. 2004: Prospects for inferring very large phylogenies by using the neighbor-joining method. Proc. Natl. Acad. Sci. USA 101: 11030-11035.

Tamura K., Dudley J., Nei M. \& Kumar S. 2007: MEGA4: Molecular Evolutionary Genetics Analysis (MEGA) software version 4.0. Mol. Biol. Evol. 24: 1596-1599.

Tu Z. 1997: Three novel families of miniature inverted-repeat transposable elements are associated with genes of the yellow fever mosquito, Aedes aegypti. Proc. Natl. Acad. Sci. USA 94: 7475-7480.

Tu Z. 2005: Insect transposable elements. In Gilbert L.I., Iatrou K. \& Gill S.S. (eds): Molecular Insect Sciences. Vol. 4. Biochemistry and Molecular Biology. Elsevier, Amsterdam, pp. $395-474$.

Tu Z. \& Orphanidis S.P. 2001: Microuli, a family of miniature subterminal inverted-repeat transposable elements (MSITEs): Transposition without terminal inverted repeats. Mol. Biol. Evol. 18: 893-985.

Turcotte K. \& Bureau T. 2002: Phylogenetics analysis reveals Stowaway-like elements may represent a forth family of the IS630-Tc1-marniner superfamily. Genome 45: 82-90.

UnSAL K. \& Morgan G.T. 1995: A novel group of families of short interspersed repetitive elements (SINEs) in Xenopus: evidence of a specific target site for DNA-mediated transposition in inverted-repeat SINEs. J. Mol. Biol. 248: 812-823.

Vermunt A.M.W., Koopmanschap A.B., Vlak J.M. \& de Kort C.A.D. 1998: Evidence for two juvenile hormone esteraserelated genes in the Colorado potato beetle. Insect Mol. Biol. 7: $327-336$.

Waterston R. \& Sulston J. 1995: The genome of Caenorhabditis elegans. Proc. Natl. Acad. Sci. USA 92: 10836-10840.

De Wilde J., DuintJer C.S. \& Mook L. 1959: Physiology of diapause in the adult Colorado beetle - I. The photoperiod as a controlling factor. J. Insect Physiol. 3: 75-85.
Yang G., Dong J., Chandrasekharran M.B. \& Hall T.C. 2001: Kiddo, a new transposable element family closely associated with rice genes. Mol. Genet. Genomics 266: 417-424.

YeAdon P.J. \& CAtcheside D.E. 1995: Guest: a 98 bp invert repeat transposable element in Neurospora crassa. Mol. Gen. Genet. 247: 105-109.

Yocum G.D. 2001: Differential expression of two HSP70 transcripts in response to cold shock, thermoperiod, and adult diapause in the Colorado potato beetle. J. Insect Physiol. 47: 1139-1145.

Yocum G.D. 2003: Isolation and characterization of three diapause-associated transcripts from the Colorado potato beetle, Leptinotarsa decemlineata. J. Insect Physiol. 49: 161-169.

Yocum G.D., Rinehart J.P., Chirumamilla-Chapara A. \& LARSON M.L. 2009a: Characterization of gene expression patterns during the initiation and maintenance phases of diapause in the Colorado potato beetle, Leptinotarsa decemlineata. $J$. Insect Physiol. 5: 32-39.

Yocum G.D., Rinehart J.P. \& Larson M.L. 2009b: Downregulation of gene expression between the diapause initiation and maintenance phases of the Colorado potato beetle, Leptinotarsa decemlineata (Coleoptera: Chrysomelidae). Eur. J. Entomol. 106: 471-476.

Yu J., Hu S., Wang J., Wong G.K.-S., Li S. et al. 2002: A draft sequence of the rice genome (Oryza sativa L. ssp. indica). Science 296: 92-100.

Zhang X., Feschotte C., Zhang Q., Jiang N., Eggleston W.B. \& WeSSLER S.R. 2001: P instability factor: an active maize transposon system associated with the amplification of Tourist-like MITEs and a new superfamily of transposon. Proc. Natl. Acad. Sci. USA 98: 12572-12577.

ZUKER M. 2003: Mfold web server for nucleic acid folding and hybridization prediction. Nucl. Acids Res. 31: 3406-4315.

ZuKer M., Mathews D.H. \& Turner D.H. 1999: Algorithms and thermodynamics for RNA secondary structure prediction: A Practical Guide. In Barciszewski J. \& Clark B.F.C. (eds): RNA Biochemistry and Biotechnology. NATO ASI Series, Kluwer Academic Publishers, Dordrecht, pp. 11-43.

Received September 16, 2010; revised and accepted November 19, 2010 